\title{
EVALUATION AND COMPARISON OF DPSIR FRAMEWORK AND THE COMBINED SWOT - DPSIR ANALYSIS (CSDA) APPROACH: TOWARDS EMBRACING COMPLEXITY
}

\author{
SKONDRAS N.A. ${ }^{1}$ \\ KARAVITIS C.A. ${ }^{1, *}$
}

Received: $22 / 07 / 2014$

Accepted: 29/07/2014

Available online: 03/03/2015
Department of Natural Resources Development \& Agricultural Engineering Agricultural University of Athens, Greece

*to whom all correspondence should be addressed: e-mail: ckaravitis@aua.gr

\section{ABSTRACT}

Natural resources management needs to deal with multiple and usually conflicting issues in order to satisfy equally opposing objectives for the physical systems sustainable development. In such a complex field, decision making may become quite challenging and pressing particularly in times of crises, such as environmental and climatic uncertainties or economic instabilities. Thus, decision makers should be provided with sufficient information regarding both the system and the problem at hand in order to cope with the inherent complexity and develop timely, efficient and implementable corresponding actions. The quest for reliable applicable options has resulted in developing and implementing various concepts, methodologies, frameworks and tools. In this context, a decision support tool/framework that derives from the well-established and widely applied DPSIR framework is presented. The framework (Combined SWOT-DPSIR Analysis - CSDA) introduces some new elements in the ordinary DPSIR analysis and aims at facilitating decision makers in their efforts to embrace ecosystems' complexity. The framework is also compared against its predecessor through multiple criteria decision analysis. The main objective of the comparison is to highlight potential differences of the presented framework and to provide additional details on its structure. As a result, it may lead towards a better understanding of the nascent systems complexity.

Keywords: Decision Making, Decision Support Tools, DPSIR Framework, CSDA Approach, Information, Complexity.

\section{Introduction}

Environmental and natural resources management (ENRM) may be defined as a process that focuses on the interrelations and interactions between human (social and economic) and physical (ecological) systems (Alexander, 2007). In the pertinent literature, both these systems have been described as extremely complex (Berkes and Folke, 1998). During the last decades, their combined properties and aspects are considered as composing the main unit of analysis and have been named social-ecological systems (Berkes and Folke, 1998; Berkes et al., 2003) or coupled human-environmental systems (Turner et al., 2003). The complexity of the coupled systems emerges from a series of factors including the great number of tight relations among the various systemic components and the occurring feedbacks (Kirchner, 2002; Heylighen, 2008), the systems' dynamic behavior and evolution (Lorenz, 1963; Berkes and Folke, 1998; Berkes et al., 2003) as well as the emergent systemic properties that occur due to the synergy of the combined elements and non-linearity (DuFrene, 2006; Heylighen, 2008). 
In this context, the process of ENRM seeks to identify the desired and sustainable environmental outcome given the physical, economic, technological and social limitations and obstacles including the intrinsic complexity of the coupled systems as well as the diverging and conflicting objectives set by various groups of stakeholders (Erickson and King, 1999; El-Kholy, 2001; Delmas and Toffel, 2004; Barrow, 2006). Under such circumstances, decision making processes are called upon to play a crucial role in the identification from a large number of feasible alternatives the set of actions which best accomplish the overall objectives (Daellenbach, 1994; Corvalán et al., 2000; Bianco, 2006; Qudrat-Ullah et al., 2008; Adair, 2010). Nevertheless, decision making in that particular context, is a challenging task and may become extremely pressing in times of crises, such as environmental uncertainties and climatic vagaries or economic instabilities that force decision makers to develop timely, efficient and implementable corresponding implementable actions in order to enhance the systems' strengths in a time constraining setting.

In cases such as these, decision makers need to be equipped with sufficient information regarding both the system and the problem at hand (Adam and Humphreys, 2008; Morçöl, 2007). In this context they might be able to cope with complexity and the various obstacles as well as to maximize the benefits from any natural resource project through a larger systemic analysis of the surrounding environment, the broadening of the traditional narrow planning and management approaches and finally, to achieve an increased sensitivity to decision-making problems associated with multi-objective, multi-purpose actions and multi-uses/users considerations (Karavitis, 2008). More specifically, decision makers need to get information about the system's state, organization, functioning, its key attributes and properties as well as the potential of the system to react to threats. In this regard, the descriptive capacity of some concepts such as resilience and vulnerability may provide the desired information (Adger and Kelly, 1999; Folke et al., 2002; Leichenko and O'Brien, 2002).

In the quest for information, during the last decades, various concepts, methodologies, frameworks and tools have been developed and applied including Environmental Impact Assessment (Glasson et al., 1999; Moberg, 1999; Finnveden and Moberg, 2005), Strengths, Weaknesses, Opportunities, Threats (SWOT) Analysis (Kheng-Hor and Munro-Smith, 1999; Dyson, 2004; Paliwal, 2006), Political, Economic, Social, Technological, Legal, Ecological (PESTLE) Analysis (Recklies, 2006), and Driving Forces, Pressures, State, Impacts, Responses (DPSIR) Framework (EPA, 1995; EEA, 1999; Kristensen, 2004; Carr et al., 2007). The selection of the most appropriate approach or set of approaches depend on the system, the desired results, the available resources and data, the required knowledge base and experience as well as the nature of the problem at hand.

In this context, a decision support tool/framework that derives from the well-known and widely applied DPSIR framework has been developed and presented. The framework, named; Combined SWOT-DPSIR Analysis (CSDA), introduces new elements in the ordinary DPSIR analysis and aims at facilitating decision makers in their efforts to embrace the complexity of coupled human-environmental systems by trying to provide, as previously mentioned, integrated information on the system's state, organization, functioning, its key attributes and properties as well as the potential of the system to react to threats. The framework is also compared against its predecessor through multiple criteria decision analysis. The main objective of the comparison is not to highlight the superiority of the presented framework but to offer additional details on its structure in terms of an already well-known framework. Thus, the comparison composes on one hand an alternative way of listing the properties of the presented framework while on the other it delineates the similarities and differences between the two frameworks.

\section{Description of the Frameworks}

\subsection{The DPSIR Framework}

The Drivers-Pressures-State-Impacts-Responses (DPSIR) framework was developed by the U.S. Environment Protection Agency (1995) and further expanded by the European Environmental Agency (EEA, 1999; Carr et al., 2007; Tscherning et al., 2012) in order to replace the previous forms of PressuresState-Responses (PSR) proposed by the Organization for Economic Cooperation and Development (OECD, 
1994; Carr et al., 2007), and Driver-State-Response (DSR) proposed by United Nations (UN, 1996). The main objective of the replacement was the enhancement of the comparatively limited capacity of the previous forms in terms of describing and formalizing the observed relations between the environment and human activities (Giupponi, 2002; Karavitis, 2002; Kristensen, 2004).

The DPSIR framework, as illustrated in Figure 1, is a causal chain consisting of five elements. These have been described in depth throughout pertinent literature. Briefly (EEA, 1999; Giupponi, 2002; Kristensen, 2004; Carr et al., 2007; Wood and van Halsema, 2008 Tscherning et al., 2012):

The driving forces consist of any natural (biophysical) or human-induced (socio-economic) factors that can lead to environmental pressures. The demand for agricultural land, energy, water, food, transport and housing can serve as examples of driving forces (Giupponi, 2002; Kristensen, 2004; Wood and van Halsema, 2008). Pressures consist of the driving forces' consequences on the environment such as the exploitation of resources (land, water, minerals, fuels, etc.), pollution and the production of waste or noise (Wood and van Halsema, 2008). As a result of pressures, the 'state' of the environment is affected; that is, the quality of the various natural resources (air, water, soil, etc.) in relation to the functions that these resources fulfill. The 'state of the environment' is thus the combination of the physical, chemical and biological conditions. The support of human and non-human life as well as the depletion of resources can serve as pertinent examples (Kristensen, 2004). Changes in the state may have an Impact on human health, ecosystems, biodiversity, amenity value, financial value, etc. Impact may be expressed in terms of the level of environmental harm and finally, the responses demonstrate the social efforts to solve the problems identified by the assessed impacts, e.g. policy measures, and planning actions (EEA, 1999; Giupponi, 2002; Kristensen, 2004; Wood and van Halsema, 2008).

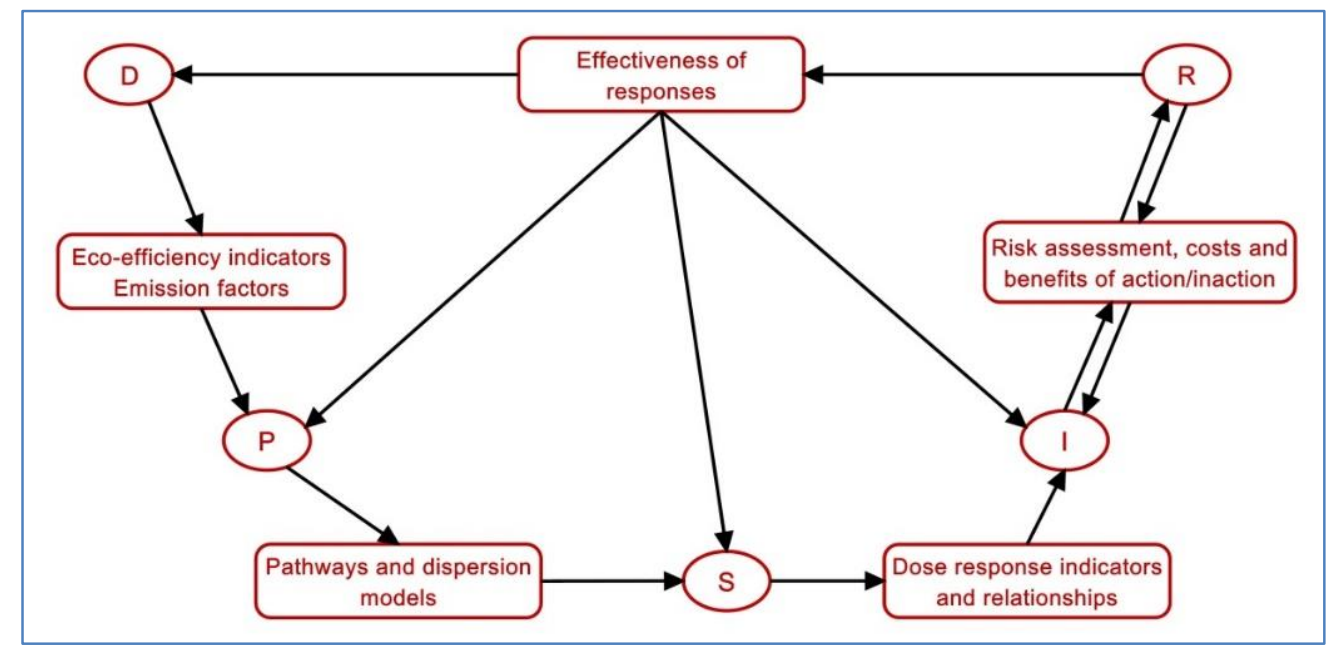

Figure 1. Indicators and information linking the DPSIR elements (EEA, 1999)

To date, DPSIR has been proved as a valuable tool that describes the relationships between the origins and consequences of environmental problems (Leka et al., 2005), provides a significant fraction of the necessary environmental information (EUROSTAT, 1999), facilitates decision making (Tscherning et al., 2012) and promotes the core essence of environmental sustainability (Reed et al., 2006). As a result, it has been applied in numerous research efforts - including Water Resources Management - of various scales as well as in a series of international and multidisciplinary research projects as the main analysis tool (Tscherning et al., 2012). The wide acceptance of the framework may be demonstrated by the fact that the majority of indicator groups which have been used by national and international agencies are based on it as presented in Figure 1 (Leka et al., 2005).

In the majority of the applications, the framework had to undergo a series of modifications and adjustments so to adapt to every facing issue. The simple linear structure facilitated such modifications 
since its embodied simplicity guarantees maximum adaptability to numerous management cases and their variations making the framework ideal for simple as well as for partially complex analysis.

Nevertheless, and based on the previously described structure, that conceptual framework has been criticized due to the hierarchy, simplicity, causality and linearity it displays. According to that criticism, DPSIR cannot actually describe and completely cope with the inherent complexity (Pahl-Wolst, 2007) and the implied uncertainty (Doremus et al., 2011) that is always present in natural resources systems. More specifically, it cannot represent a complex non-linear reality.

Furthermore, a great number of the interrelations between the natural system and the socio economic system are not known, or are only minimally understood or described. Additionally, it cannot describe the various feedbacks - negative or positive - that take place in or out of a system, unless it is properly reformed (e.g. Vacik et al., 2006; Niemeijer and de Groot, 2008), meaning, for example, that the transformation of an impact - generated by a pressure - into another pressure cannot be described. Such a factor would produce a more complex approach or tool with the potential to provide decision makers with a greater fraction of the necessary information.

Finally, the framework does not focus on the inner resilience and/or vulnerability of the system as parts of the system's state. This means that the DPSIR Framework does not account for the factors that can affect the impacts of a pressure or the pressure itself. It seems that more research should go into developing a potentially more representative methodological framework. A step towards that direction is attempted with the development of the following framework.

\subsection{The CSDA Framework}

The Combined SWOT - DPSIR Analysis (CSDA - Figure 2) is a newly developed framework that derived from the ordinary form of DPSIR (Skondras, 2009).

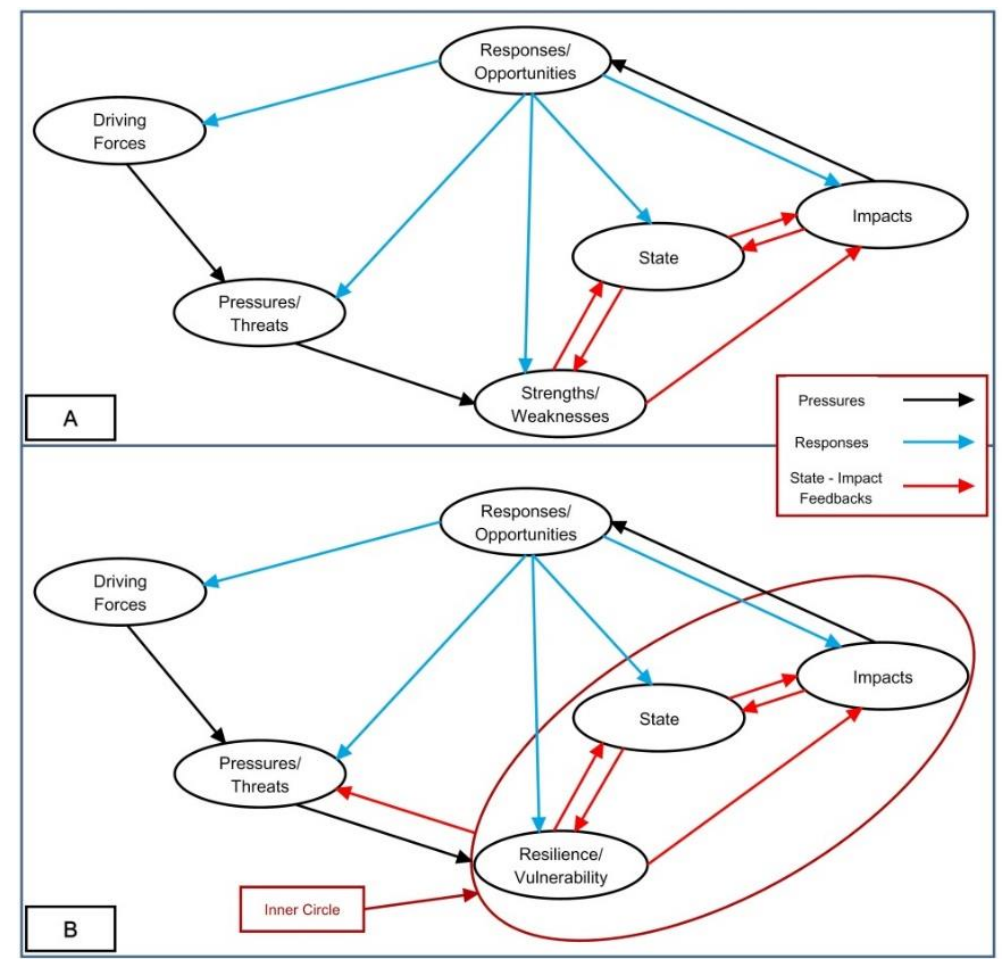

Figure 2. The CSDA framework. A: initial phase and, B: final phase of development (Skondras, 2009)

Considering the numerous transformations and replacements that occurred within the DPSIR history of evolution, the development of a sequential/subsequent and related framework should come as no surprise. As a framework, it has been enhanced with elements adopted from SWOT analysis and Multi- 
Criteria Analysis (MCA - the analysis of multiple factors of equal or differentiated importance) as well as from the concepts of resilience and vulnerability.

It is believed that it can overrun the problems and the observed inefficiency of the DPSIR Framework and that it may produce more practicable results. The CSDA framework was conceived in order to address the whole planning/decision making procedure as it is presented in Figure 3, and therefore, it may be used as an autonomic integrated method during the decision making process.

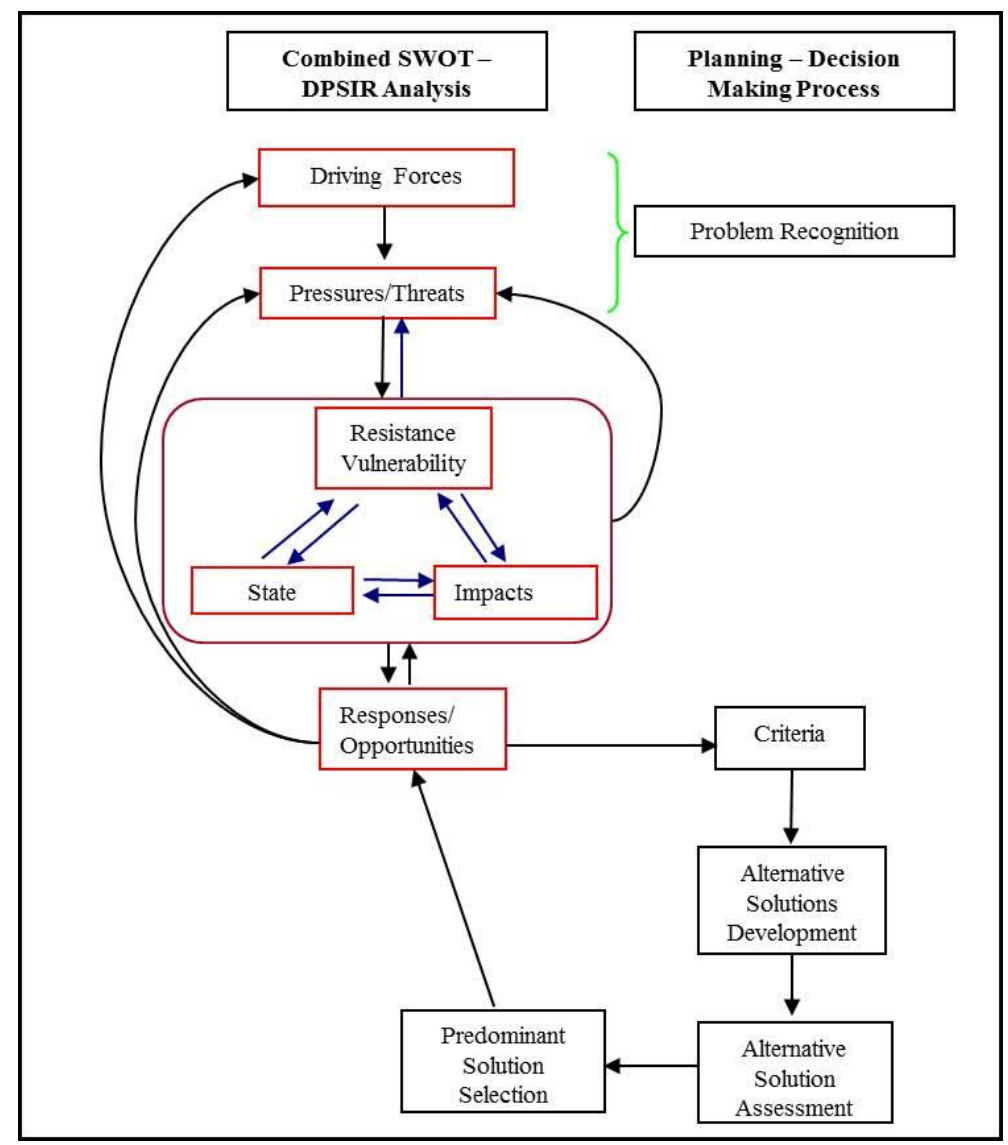

Figure 3. The CSDA framework parallelized with the planning/decision making process

The combination of SWOT analysis and DPSIR framework creates two "circles". The external circle that derives from the DPSIR elements within the framework and refers to the external conditions that affect/press the system of interest, and the internal circle that derives from the SWOT elements within the framework and refers to the internal systemic factors that are used for the pressure to be minimized (absorbed) or maximized (amplified) before the pressure's transformation into impacts. The latter circle is considered as the most important element of the CSDA framework. More specifically, the circle is composed of the systemic strengths and weaknesses and determines the degree of the state quality shifting, the Impacts' weight of stress and the severity or immediacy of the responses (Skondras, 2009).

The development of the framework is based on the assumption that under the same pressures (external conditions), two systems will react differently having different inner resistances. The inner systemic resistances, likewise SWOT analysis, are created and shaped through time under the impacts of natural and non-natural forces. For example: two rivers with different water flow velocity (inner factor which may mean different slopes or different water supply) react differently under the pressure of the same waste disposal. Another example is that for a future pressure it is important to know whether the system (on which the pressure will act) is already degraded (inner weakness) or not (inner strength).

The resilience and vulnerability (Figure 2B) concepts have been added to the framework by expanding the meaning of the terms strengths and weaknesses respectively. More and more, the terms of resilience and 
vulnerability as well as their related ones including adaptive capacity, transformation, etc. appear in the environmental and/or social change literature (Janssen et al., 2006) meaning that the respective concepts are of growing interest among the researchers. According to Miller et al., (2010) and de Chazal (2010), and despite the fact that vulnerability and resilience concepts derived from different approaches and thought patterns, and focus on different dimensions of the examined issue [social-political (Folke, 2006; Gallopín, 2006) and ecological-biophysical (Eakin and Luers, 2006; McLaughlin and Dietz, 2007) respectively], both concepts display some relevant links and similarities. Additionally, according to Miller et al. (2010), the combined analysis and application of resilience and vulnerability may promote systems knowledge and understanding.

The use of such an expanded concept may seem complicated since a system usually gets more than one pressures at the same time (sometimes the pressures merge and create a new pressure). Thus, the elements that determine the system's resilience for one pressure can be transformed into vulnerability elements for another pressure. In that case, each pressure has to be examined separately using already well-established tools such as indices, environmental impact assessment, cost-benefit analysis, multicriteria analysis etc. Then the results have to be combined as in a puzzle. That particular approach may underestimate the complexity and the synergetic properties among the various pressures yet; the combined effects of statistical analysis and contingency planning may produce satisfactory results.

Finally, the CSDA framework was designed in an attempt to address non-linearity and feedbacks among the various composing elements and more specifically between the impacts and pressures as well as between the responses and pressures. This may be translated that an impact or the responses against a pressure can sequentially be transformed into a new pressure. This phenomenon can be displayed graphically by the pertinent arrows between the categories: pressures-state-resilience/vulnerabilityimpacts-responses (Figures 2 and 3). Consequently, the CSDA embraces the properties of a dynamic approach and needs to be repeated over and over again until the analysis reached the desired results under the constraints of certain resources such as time, lack of data, or even lack of specialized knowledge.

\section{Comparison between the Frameworks}

The CSDA framework is compared against its predecessor through multiple criteria decision analysis. The main objective of the comparison is to provide additional details on the CSDA structure in regard to an already well-known framework. More specifically, the comparison composes an alternative way of listing the properties of the presented framework as well as the similarities and differences between the two frameworks.

\subsection{Identification of Criteria}

The comparison is based on the following criteria / properties of the frameworks. Namely:

1. Complexity embracing: The frameworks' ability to deepen into the system's complexity and promote understanding of the various relations among the interfering factors of interest in differentiated temporal and spatial (in and out) scales.

1.1. Emphasis on the external environment - Max: Explanation and description of how the system's external environment affects the system itself (pressure creation).

1.2. Emphasis on the internal environment - Max: Explanation and description of the system's inner strengths (resilience) and weaknesses (vulnerability) as they have been shaped by time until the moment an external pressure occurs.

1.3. Emphasis on the internal - external environmental relations (feedbacks) - Max: Explanation and description of how the various pressures affect the system and how the system's strengths (resilience) and weaknesses (vulnerability) affect the external pressures or the state and impacts these pressures create. This criterion also focuses on the frameworks ability to explain and describe how some of the impacts of an initial pressure can be transformed into a new pressure.

2. Data Criteria: These criteria refer to the quantity of required data and to the relations among them. 
2.1. Quantity of data - Max: The criterion refers to the quantity of the required data without counting on the data availability. The criterion is based on the acknowledgement that more data create greater wealth of information and a clearer view of the system.

2.2. Data relations - Max: The criterion refers to the data usage and is based on the fact that the same data combination can be used for different purposes. For example knowing the flora species of an area someone may understand: $\mathbf{a}$. how these species would be affected by a pressure and $\mathbf{b}$. how these species can affect the pressure.

\section{General Criteria:}

3.1. Application range - Max: The criterion focuses on how many different environmental management cases can the framework be used. For example water resources management or forest resources management.

3.2. Specialized knowledge use - Min: The criterion refers to the difficulty of using the frameworks. A framework that does not require specialized knowledge can be used by a single researcher or a small group. On the other hand a method that requires specialized knowledge can be used only by large groups or organizations with the use of specialized data and other specialized secondary tools.

3.3. Time constraints - Min: The criterion refers to the application of the frameworks under time constraints. The simpler the framework is, the lesser time it requires for the results to be produced.

3.4. Cost of application - Min: The criterion refers to the cost of application. A framework that requires smaller amount of data as well as less specialized knowledge or smaller groups of researchers will require lesser funding for the application.

The criteria will be tested under different weighting cases. For every weighting case of the main criteria $(1,2$, and 3$)$, the sub-criteria $(1.1,1.2,1.3,2.1$, etc.) will be tested under three distinct weighting cases (Figure 4). The weights per case are presented in Table 1 and the empirical performance (scale 1 - worst to 5 - best) per framework is presented in Table 2. All in all, 21 weighting cases were tested.

Table 1. Weights per case of main and sub-criteria

\begin{tabular}{cccc}
\hline Main Criteria & $\mathbf{1}$ & $\mathbf{2}$ & $\mathbf{3}$ \\
\hline Case 1 & 1.00 & 1.00 & 1.00 \\
\hline Case 2 & 1.50 & 1.00 & 0.50 \\
\hline Case 3 & 1.00 & 0.50 & 1.50 \\
\hline Case 4 & 0.50 & 1.50 & 1.00 \\
\hline Case 5 & 2.00 & 1.00 & 1.00 \\
\hline Case 6 & 1.00 & 2.00 & 1.00 \\
\hline Case 7 & 1.00 & 1.00 & 2.00 \\
\hline Sub-Criteria & Case A & Case B & Case C \\
\hline Sub-criterion 1.1 & 0.333 & 0.25 & 0.35 \\
\hline Sub-criterion 1.2 & 0.333 & 0.25 & 0.35 \\
\hline Sub-criterion 1.3 & 0.333 & 0.50 & 0.30 \\
\hline Sub-criterion 2.1 & 0.50 & 0.75 & 0.25 \\
\hline Sub-criterion 2.2 & 0.50 & 0.25 & 0.75 \\
\hline Sub-criterion 3.1 & 0.25 & 0.40 & 0.10 \\
\hline Sub-criterion 3.2 & 0.25 & 0.20 & 0.30 \\
\hline Sub-criterion 3.3 & 0.25 & 0.20 & 0.30 \\
\hline Sub-criterion 3.4 & 0.25 & 0.20 & 0.30 \\
\hline
\end{tabular}


Table 2. Performance per framework

\begin{tabular}{l|c|c}
\hline \multicolumn{1}{c|}{ Sub-Criteria } & Frameworks' performance \\
\cline { 2 - 3 } & DPSIR & CSDA \\
\hline 1.1.Emphasis on the external environment & 4 & 4 \\
\hline $\begin{array}{l}\text { 1.2.Emphasis on the internal environment } \\
\text { 1.3.Emphasis on the internal - external environmental } \\
\text { relations (feedbacks) }\end{array}$ & 2 & 4 \\
\hline 2.1.Quantity of data & 2 & 4 \\
\hline 2.2.Data relations & 3 & 4 \\
\hline 3.1.Application range & 4 & 4 \\
\hline 3.2.Specialized knowledge use & 4 & 2 \\
\hline 3.3.Time constraints & 4 & 2 \\
\hline 3.4. Cost of application & 4 & 2 \\
\hline
\end{tabular}

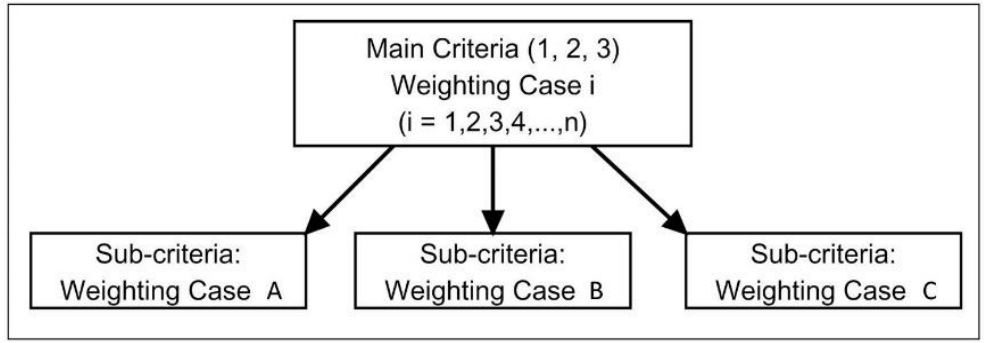

Figure 4. Structure of the weighting cases

\subsection{Multi-Criteria Analysis}

For the comparison purposes two different MCDA methods are used. More specifically:

1. Weighted Average Method (WAM): One of the most common MCDA methods. The score for an alternative $(j)$ is defined as the summation of the products of the normalized weights (W) times the rating $(R)$ for each criterion (i) (Fontane, 2003 - Equation 1).

$S_{j}=\sum_{i=1}^{4} W_{i} \times R_{i, j}$

2. PROMETHEE II: Out-ranking method where pair-wise comparisons of all the alternatives take place. In the pure application of the method, the procedure is applied to each of the sub-criterion. The range of indifference was set to zero resulting in a strict preference structure (Brans et al., 1986; Fontane, 2003).

The model used for the application was developed by Fontane, 2003. The results are presented on the next section. -

\subsection{Results}

The comparison results are presented in detail on Table 3 and Figures 5 and 6 .

Based on the produced results of Table 3, and for the MCDA-WAM process, the CSDA framework prevails in almost all cases where time constraints, the use of specialized knowledge and the cost of application are of low importance ( $3 A$ and $C$ as well as $7 A$ and $C-$ Table 1 ) while displaying its maximum value in case 2B where according to Table 2, the importance of the criteria the CSDA performs better is considerably higher. On the other side, the DPSIR framework overcomes the CSDA in the examined cases where these criteria are of significant importance. On the same cases (including $3 \mathrm{~B}$ and $7 \mathrm{~B}$ - where application range is more important compared to the other three criteria of the same category) the MCDA - PROMETHEE II (pair-wise comparison) indicates equal performance between the two frameworks highlighting the DPSIR 
dominance in a different way. Similarly, the DPSIR framework displays its minimum value on the cases $2 \mathrm{~A}$, $2 \mathrm{~B}$ and $2 \mathrm{C}$.

Table 3. Results per framework, weighting case and MCDA method

\begin{tabular}{|c|c|c|c|c|}
\hline \multirow{2}{*}{ Case } & \multicolumn{2}{|c|}{ WAM } & \multicolumn{2}{|c|}{ PROM } \\
\hline & DPSIR & CSDA & DPSIR & CSDA \\
\hline $1 \mathrm{~A}$ & 3.06 & 3.50 & -0.33 & 0.00 \\
\hline $1 B$ & 2.92 & 3.60 & -0.33 & 0.00 \\
\hline $1 C$ & 3.15 & 3.40 & -0.33 & 0.00 \\
\hline $2 \mathrm{~A}$ & 2.83 & 3.75 & $-0.67(\min )$ & 0.00 \\
\hline $2 B$ & $2.67(\min )$ & 3.80 (max) & $-0.67(\min )$ & 0.00 \\
\hline $2 C$ & 2.93 & 3.70 & $-0.67(\min )$ & 0.00 \\
\hline $3 \mathrm{~A}$ & 3.31 & 3.25 & 0.00 & 0.00 \\
\hline $3 B$ & 3.21 & 3.40 & 0.00 & 0.00 \\
\hline $3 C$ & 3.36 & 3.10 & 0.00 & 0.00 \\
\hline $4 \mathrm{~A}$ & 3.03 & 3.50 & -0.33 & 0.00 \\
\hline $4 B$ & 2.88 & 3.60 & -0.33 & 0.00 \\
\hline $4 C$ & 3.16 & 3.40 & -0.33 & 0.00 \\
\hline $5 A$ & 2.96 & 3.63 & -0.50 & 0.00 \\
\hline $5 B$ & 2.81 & 3.70 & -0.50 & 0.00 \\
\hline $5 C$ & 3.04 & 3.55 & -0.50 & 0.00 \\
\hline $6 \mathrm{~A}$ & 2.92 & 3.63 & -0.50 & 0.00 \\
\hline $6 \mathrm{~B}$ & 2.75 & 3.70 & -0.50 & 0.00 \\
\hline $6 C$ & 3.05 & 3.55 & -0.50 & 0.00 \\
\hline $7 \mathrm{~A}$ & 3.29 & 3.25 & 0.00 & 0.00 \\
\hline 7B & 3.19 & 3.40 & 0.00 & 0.00 \\
\hline $7 C$ & 3.36 (max) & $3.10(\mathrm{~min})$ & 0.00 & 0.00 \\
\hline
\end{tabular}

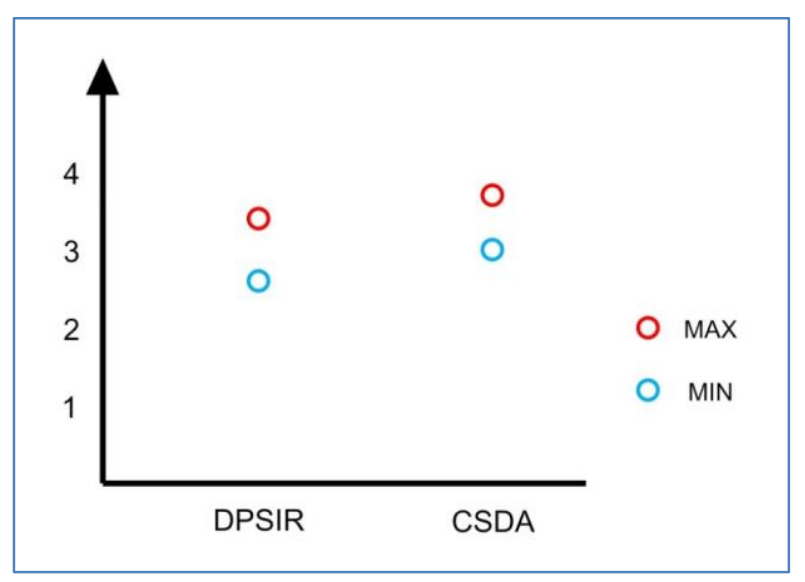

Figure 5. MCDA results using WAM

Figures 5 and 6 display the maximum and minimum values the two frameworks achieved in the analysis of all the examined cases per calculation method as these are mentioned in Table 3. According to the average value of the two MCDA methods for both CSDA (3.50 - WAM, 0.00 - PROM) and DPSIR (3.04 WAM, -0.33 - PROM), the CSDA framework displays a satisfactory behavior under the tested cases and it may be able, by embracing a larger portion of complex reality compared to its predecessor, to promote 
system understanding and facilitate decision makers develop timely, efficient and implementable corresponding actions concerning environmental and natural resources management.

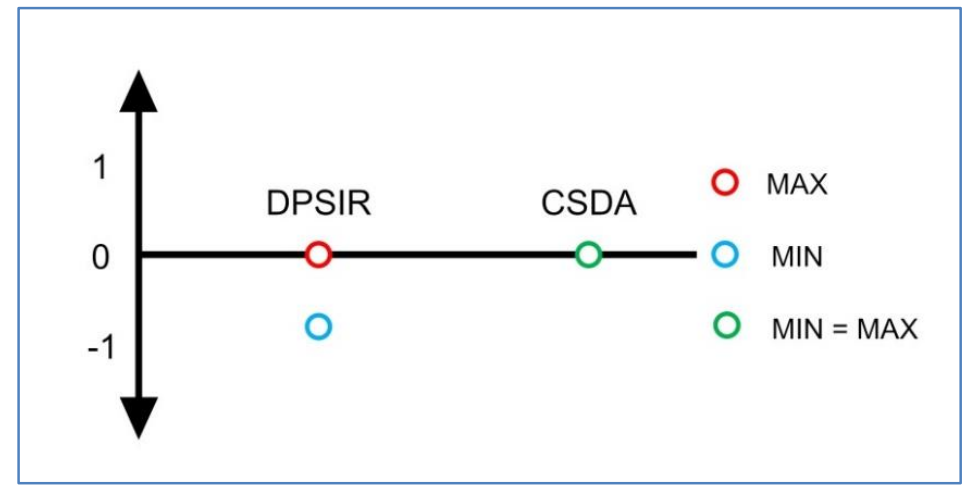

Figure 6. MCDA results using PROMETHEE II

\section{Conclusions}

The CSDA Method has not been yet fully applied and tested in field conditions and consequently it still has to prove that it may meet the purposes created for. This may well be the focus of subsequent research efforts. It is believed though that it can be used in a variety of cases just like the DPSIR framework and it may produce more appropriate results than the last one. It is also believed that it can describe an area (system, natural or not) and especially its inner conditions (strengths - weaknesses, resistance vulnerability) with adequate sufficiency. Hence, the rigidity of the responsive measures may be adjusted. In that way a better focus on the problem solutions can be achieved and in some cases time delays, waste of resources and social stresses may be avoided. All in all, it is believed that CSDA may embrace complexity in a more applicable fashion, use a larger number of data, having at the same time the ability to incorporate additional relations among them. However, this is a built in capacity, since the CSDA was designed to possess such abilities. That would be the reason why the CSDA may prevail in cases where time constraints, the use of specialized knowledge and the cost of application are of low importance. On the other side, since the CSDA framework was designed in an effort to cure inherent DPSIR characteristics, the presented comparison against that framework may be of little actual value per se. Still, the main objective of the presented comparison was not to highlight potential advantages of the presented CSDA framework but to provide additional details on its structure in regard to an already well-established framework. In this context, the comparison composed an alternative way of listing the properties of the presented framework, as well as the similarities and differences between the two frameworks. All in all, the current effort may offer some insights in confronting the need for establishing a broader perspective and interdisciplinary approaches, especially in natural resources management. Such perspectives and approaches would enable societies to account for the variety of systems affected by resources development towards a green growth posture; by considering more alternatives for systemic ecoinnovation; by incorporating an extended horizon in planning; and by always trying to anticipate the far reaching consequences of human actions in the surrounding environment.

\section{References}

Adair J. (2010), Decision Making and Problem Solving Strategies. The Sunday Times, London, Philadelphia, New Delhi.

Adam F. and Humphreys P. (Eds.) (2008), Encyclopedia of Decision Making and Decision Support Technologies. Information Science Reference, Hershey, New York.

Adger W.N. and Kelly P.M. (1999), Social Vulnerability to Climate Change and the Architecture of Entitlements, Mitigation and Adaptation Strategies for Global Change, 4, 253-266.

Alexander D. (2007), Environmental Management. In: McGraw-Hill Encyclopaedia of Science and Technology, 10th Edition, Vol. 6, pp. $601-603$. 
Berkes F., Colding J. and Folke C. (Eds.) (2003), Navigating the dynamics of social-ecological systems: building resilience for complexity and change. Cambridge University Press, Cambridge, UK.

Berkes F. and Folke C. (Eds), (1998). Linking Social and Ecological Systems: Management Practices and Social Mechanisms for Building Resilience. Cambridge University Press, Cambridge, UK.

Bianco D. (2006), Decision Making, in Encyclopedia of Management Edited by Marilyn M. Helms (2006), 5th Edition, Thomson Gale Editions. pp 160 - 164.

Brans J.P., Mareschall B. and Vincke P. (1986), How to select and how to rank projects: The PROMETHEE method for MCDM, European Journal of Operational Research, 24, 228-238.

Carr R.E., Wingard P.M., Yorty S.C., Thompson M.C., Jensen N.K. and Roberson J. (2007), Applying DPSIR to sustainable Development, International Journal of Sustainable Development \& World Ecology, 14, 543 - 555.

Corvalán C., Briggs D. and Zielhuis G. (Eds.), 2000. Decision Making in Environmental Health: From Evidence to Action. World Health Organization, London and New York.

Daellenbach H.G. (1994), Systems and Decision Making : A Management Science Approach. John Wiley \& Sons, Ltd. (UK)

Doremus H., Andreen W.L., Camacho A., Farber D.A., Glicksman R.L., Goble D., Karkkainen B.C., Rohlf D., Tarlock A.D., Zellmer S.B., Jones S. and Yee Huang Y. (2011), Making Good Use of Adaptive Management, Center for Progressive Reform White Paper \#1104

DuFrene D. (2006), Synergy, in Encyclopedia of Management Edited by Marilyn M. Helms (2006), 5th Edition, Thomson Gale Editions

Dyson R.G. (2004), Strategic development and SWOT analysis at the University of Warwick, European Journal of Operational Research, 152, 631-640.

El-Kholy O.A. (2001), Trends in environmental management in the last 40 years, in T. Munn (ed.) Encyclopedia of Global Environmental Change (vol. 4). Wiley, Chichester, pp. 25-20.

European Environment Agency (1999), Environmental Indicators: Typology and Overview. Technical Report No. 25, Copenhagen.

Environmental Protection Agency, 1995. Beyond the Horizon: Using Foresight to Protect the Environmental Future. Available at http://vosemite.epa.gov/sab/sabproduct.nsf/262190D22B82BF4F8525719B0064759E/\$File/ec95-007.pdf

Erickson S.L. and King B.J. (1999), Fundamentals of Environmental Management. Wiley, New York.

EUROSTAT (1999), Environmental Pressure indicators for the EU. First Edition. Theme 8: Environment and Energy.

Finnveden G. and Moberg A. (2005), Environmental systems analysis tools - an overview, Journal of Cleaner Production, 13(12), 1165-1173.

Folke C., Carpenter S., Elmqvist T., Gunderson L., Holling C.S., Walker B., Bengtsson J., Berkes F., Colding J., Danell K., Falkenmark M., Gordon L., Kaspersson R., Kautsky N., Kinzig A., Levin S.A., Mäler K.-G., Moberg F., Ohlsson L., Olsson P., Ostrom E., Reid W., Rockström M.J., Savenije H. and Svedin U. (2002), Resilience and sustainable development: building adaptive capacity in a world of transformations. Report for the Swedish Environmental Advisory Council 2002:1. Ministry of the Environment, Stockholm, Sweden.

Fontane D.G. (2003), Introduction to Multi-Criterion Decision Analysis, Class-notes, Colorado State University, Fort Collins, CO. USA.

Giupponi C. (2002), From the DPSIR reporting framework to a system for a dynamic and integrated decision making process. International MULINO Conference on "European policy and tools for sustainable water management" Island of San Servolo, Venice, Italy, November 21-23.

Glasson J., Therivel R. and Chadwick A. (1999), Introduction to Environmental Impact Assessment. Principles and procedures, process, practice and prospects. 2nd Edition. The Natural and Built Environment Series. T.J. International Ltd, Padstow, UK.

Heylighen F. (2008), Complexity and Self Organization, in Encyclopedia of Library and Information Sciences edited by Marcia J. Bates and Mary Niles Maack, Taylor and Francis Editions.

Janssen M.A. Schoon M.L., Ke W. and Börner K. (2006), Scholarly networks on resilience, vulnerability and adaption within the human dimensions of global environmental change, Global Environmental Change, 16, $240-252$. 
Karavitis C.A. (2002) Invited Speaker. Policies and tools for Sustainable Water Management in the EU, International MULINO Conference on "European policy and tools for sustainable water management", Island of San Servolo, Venice, Italy, November 21-23.

Karavitis C.A. (2008), Water Use in Europe. Booklet Series: B, Number: 5. In: "Land care in desertification affected areas: from science towards application" (LUCINDA) Specific Support Action, DG-Research-1163, Global Change and Ecosystems, $15 \mathrm{p}$.

Kheng-Hor K. and Munro-Smith N. (1999), Reader-Friendly Strategic Management: A delightful blend of academic learning and Street-smart practices. Selangor Darul Ehsan: Pelanduk Publications.

Kirchner J.W. (2002), The Gaia Hypothesis: Fact, Theory and Wishful Thinking, Climatic Change, 52, 391 - 408.

Kristensen P. 2004, The DPSIR Framework. National Environmental Research Institute, Denmark. European Topic Centre, European Environment Agency.

Leichenko R.M. and O'Brien K.L. (2002), The dynamics of rural vulnerability to global change: The case of Southern Africa, Mitigation and Adaptation Strategies for Global Change, 7, 1-18.

Leka A., Goumas S. and Cassios C. (2005), The Modern Role and Importance of Using Environmental Indicators as a Key Tool in Environmental Management, Heleco '05, Greek Technical Chamber, Athens, Greece.

Lorenz E. (1963), Deterministic Nonperiodic Flow, Journal of the Atmospheric Sciences, 20, 130 - 141.

Miller F., Osbahr H., Boyd E., Thomalla F., Bharwani S., Ziervogel G., Walker B., Birkmann J., van der Leeuw S., Rockström J., Hinkel J., Downing T., Folke C. and Nelson D. (2010), Resilience and vulnerability: Complementary or conflicting Concepts?, Ecology and Society, 15(3) art 11 [online], URL: http://www.ecologyandsociety.org/vol15/iss3/art11/

Moberg A. (1999), Environmental Systems Analysis Tools: Differences and Similarities. Master Degree Thesis in Natural Resources Management. Department of Systems Ecology, University of Stockholm, Sweden.

Morçöl G., Editor. 2007. Handbook of Decision Making. CRC Press, Taylor and Francis Group.

Niemeijer D. and de Groot R.S. (2008), Framing environmental indicators: moving from causal chains to causal networks, Environment, Development and Sustainability, 10, 89 - 106.

Organization for Economic Co-operation and Development (OECD), 1994. Environmental Indicators: OECD Core Set. Paris.

Pahl-Wolst C. (2007), Transitions towards adaptive management of water facing climate and global change, Water Resources Management, 21, 49-62.

Paliwal R. (2006), EIA practice in India and its evaluation using SWOT analysis, Environmental Impact Assessment Review, 26(5), 492 - 510.

Qudrat-Ullah H., Spector J.M.n and Davidsen P.I. (Eds.), 2008. Complex Decision Making: Theory and Practice. Springer Berlin, Heidelberg, New York.

Recklies D. (2006), PEST Analysis, Available at: http://www.themanager.org/Models /PEST_Analysis.htm

Reed M.S., Fraser E.D.G. and Gougill A.J. (2006), An adaptive learning process for developing and applying sustainability indicators with local communities, Ecological Economics, 59, 406-418.

Skondras N. (2009), Application of Multi - Criteria Analysis for the Decision Making of the Environmental Protection of Shinias - Marathonas National Park, Attica, Greece. Master Thesis. Department of Natural Resources Development and Agricultural Engineering, Agricultural University of Athens, Greece.

Tscherning K., Helming K., Krippner B., Sieber S. and Gomez y Paloma S. (2012), Does research applying the DPSIR framework support decision making?, Land Use Policy, 29(1), 102-110.

United Nations (UN), 1996. Indicators of sustainable development: Framework and Methodologies. Report. 428.

Vacik H., Wolfslehner B., Seidl R. and Lexer M. (2006), Integrating the DPSIR - approach and the Analytic Network Process for the assessment of forest management strategies, in Sustainable Forestry: from Monitoring and Modelling to Knowledge Management and Policy Science (eds Reynolds K.M., Thomson A.J., Köhl M., Shannon M.A., Ray D. and Rennolls K.)

Wood A. and van Halsema G. (2008), Scoping agriculture-wetland interactions Towards a sustainable multipleresponse strategy, FAO Water Reports No 33. 